\title{
Early Emergency Responses of the Japan Atomic Energy Agency against the Fukushima Daiichi Nuclear Power Station Accident in 2011
}

\author{
Hiroshi Okuno, Sohei Sato, Takeshi Kawakami, Kazuya Yamamoto, Tadao Tanaka \\ Nuclear Emergency Assistance and Training Center, Sector of Nuclear Safety Research and Emergency Preparedness, Japan Atomic Energy Agency, Tokai- \\ mura, Japan
}

\section{Technical Paper}

Received August 28, 2020

Revision December 21, 2020

Accepted February 19, 2021

Corresponding author:Tadao Tanaka

Japan Atomic Energy Agency, 11601-13 Nishijusanbugyo, Hitachinaka, lbaraki 311-1206, Japan

E-mail: tanaka.tadao26@jaea.go.jp

(1D https://orcid.org/0000-0001-9797-9080

This is an open-access article distributed under the terms of the Creative Commons Attribution License (http://creativecommons.org/licenses/by-nc/4.0), which permits unrestricted use, distribution, and reproduction in any medium, provided the original work is properly cited.

Copyright $\odot 2021$ The Korean Association for Radiation Protection

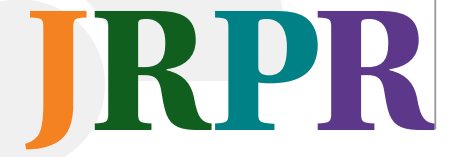

Background: The Japan Atomic Energy Agency (JAEA) is specified in the Disaster Countermeasures Basic Act as a designated public corporation for dealing with nuclear disasters.

Materials and Methods: The Nuclear Emergency Assistance and Training Center (NEAT) was established in 2002 as the activity base providing technical assistance to both national and local governments during nuclear emergencies. The NEAT has a robust structure and utilities and special installations, and it organizes training and exercises.

Results and Discussion: Due to an offshore earthquake that caused a devastating tsunami in March 2011, a nuclear accident occurred at the Tokyo Electric Power Company's Fukushima Daiichi Nuclear Power Station. The NEAT responded by conducting off-site environmental radiation monitoring and contamination screening, dispatching special vehicles, offering telephone consultations, and calculating the dispersion of radioactive materials. An examination of the emergency response activities revealed that the organization was prepared for these types of disasters and was able to plan long-term response.

Conclusion: As a designated public corporation, the JAEA technically supports the national government, the Fukushima prefectural government, and the Ibaraki prefectural government, all of which responded to the off-site emergencies resulting from the March 2011 Fukushima Daiichi accident

Keywords: Earthquake, Accident, Emergency Response, Drill, Off-site, TEPCO’s Fukushima Daiichi Nuclear Power Station

\section{Introduction}

In the national-level disaster management system of Japan, the Central Disaster Management Council (CDMC) plays the executive role of promoting comprehensive disaster countermeasures, including deliberating important issues on disaster management upon the request of the prime minister or the minister of state for disaster management. The CDMC was established in the Cabinet Office on the basis of the Disaster Countermeasures Basic Act as a council that deals with crucial policies of the Cabinet. The CDMC consists of the prime minister as the chairperson, all members of the Cabinet, heads of major designated public corporations and experts (Disaster Management in Japan, Cabinet Office, Government of Japan; http://www.bousai.go.jp/linfo/pdf/ saigaipamphlet_je.pdf). 
As a designated public corporation in the Disaster Countermeasures Basic Act, the Japan Atomic Energy Agency (JAEA) supports the national and/or local governments during nuclear incidents according to their request. Such support is provided in various technical ways, including prompt dispatch of experts for emergency radiation monitoring and provision of technical advice to governments and the public.

Historically, to accomplish these duties effectively, the Japan Nuclear Cycle Development Institute (JNC), with the cooperation of the Japan Atomic Energy Research Institute (JAERI) (the two institutes have since merged), launched the Nuclear Emergency Assistance and Training Center (NEAT) in 2002 as the organization dealing with such governmental requests. The JNC established the main office of the NEAT in Hitachinaka City, Ibaraki Prefecture, and a branch office in Tsuruga City, Fukui Prefecture [1]. Since the foundation of the JAEA in October 2005 by the merger of the JAERI and JNC, it has succeeded the operation of the NEAT.

In Materials and Methods section, the preparation of the NEAT for a nuclear emergency is summarized. Results and Discussion section explains the early response of the NEAT to the disasters that occurred off-site of the Fukushima Daiichi Nuclear Power Station (NPS), of the Tokyo Electric Power Company (TEPCO), essentially based on [2]. Then, issues regarding the response to the TEPCO's Fukushima Daiichi NPS accident (called "Fukushima Daiichi accident" herein- after) are discussed, and the final section concludes this paper.

\section{Materials and Methods}

\section{Emergency Response System of NEAT}

In March 2002, the NEAT established a system for responding to requests from the national government and/or local governments to support them technically in a nuclear emergency (Fig. 1). During such an emergency, dedicated staff members of the NEAT are reformed under the director: a shift supervisor works for 24 hours a day, 7 days a week to respond to requests from the government; the administration group addresses general requests from the government; the logistics group manages the dispatch of equipment and special vehicles; the Fukui branch is intended to play a major role if a nuclear emergency occurs in western Japan; it supports the activities of the NEAT-Ibaraki otherwise. The JAEA has chosen 120 specialists from eight expertise fields who are engaged in research or technical development in normal times as experts designated to prepare for a nuclear emergency in advance. The eight expertise fields are (1) environmental monitoring, (2) environmental assessment, (3) individual dose assessment, (4) radiation control, (5) criticality/shielding assessment, (6) nuclear transport engineering, (7) nuclear fuel engineering, and (8) reactor engineering. The JAEA will dis-

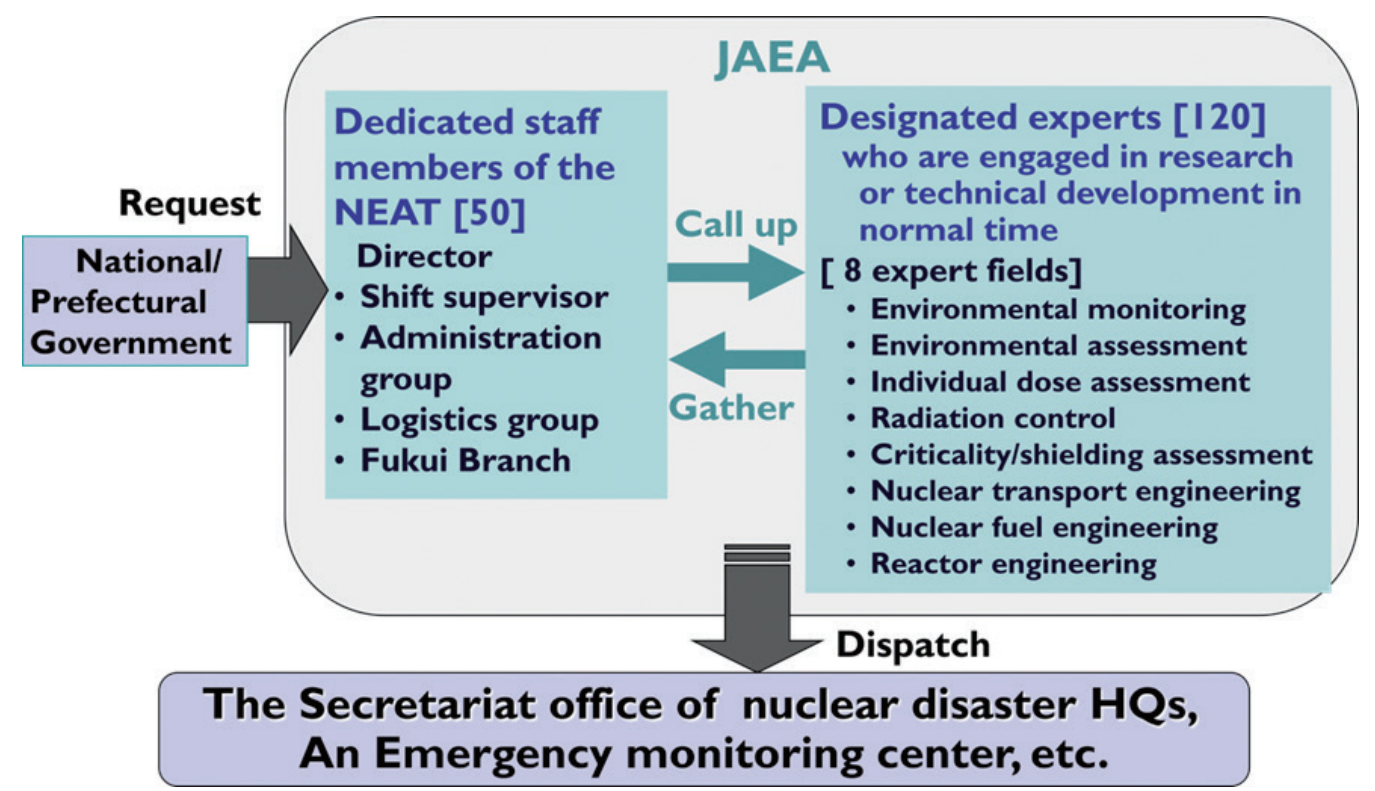

Fig. 1. Emergency response system of the Japan Atomic Energy Agency (JAEA). NEAT, Nuclear Emergency Assistance and Training Center; $H Q$, headquarter. 
patch some of these designated experts to the secretariat office of nuclear disaster headquarters, emergency monitoring centers, and similar facilities according to the nature of the emergency and the request from the government.

\section{Robust Structure/Utilities}

Given the possibility of extreme conditions, such as large earthquakes and power supply interruption, during a nuclear accident, the NEAT has installed robust systems in its main building (Emergency Assistance Building, NEATIbaraki), including a quake-absorbing structure and emergency power supply.

\section{1) Quake-absorbing structure}

A quake-absorbing structure has been installed under the Emergency Assistance Building, NEAT-Ibaraki (the site layout of the NEAT-Ibaraki is shown here: https://www.jaea. go.jp/04/shien/image/gaiyo_04e.jpg).

The quake-absorbing structure allows the building to avoid a band of vibrations that induce significant acceleration; the characteristic period of the building is extended (from 2 to 4 seconds) by the placement of laminated rubber supports and lead dampers between the building and its foundation. The lead dampers will absorb most of the energy

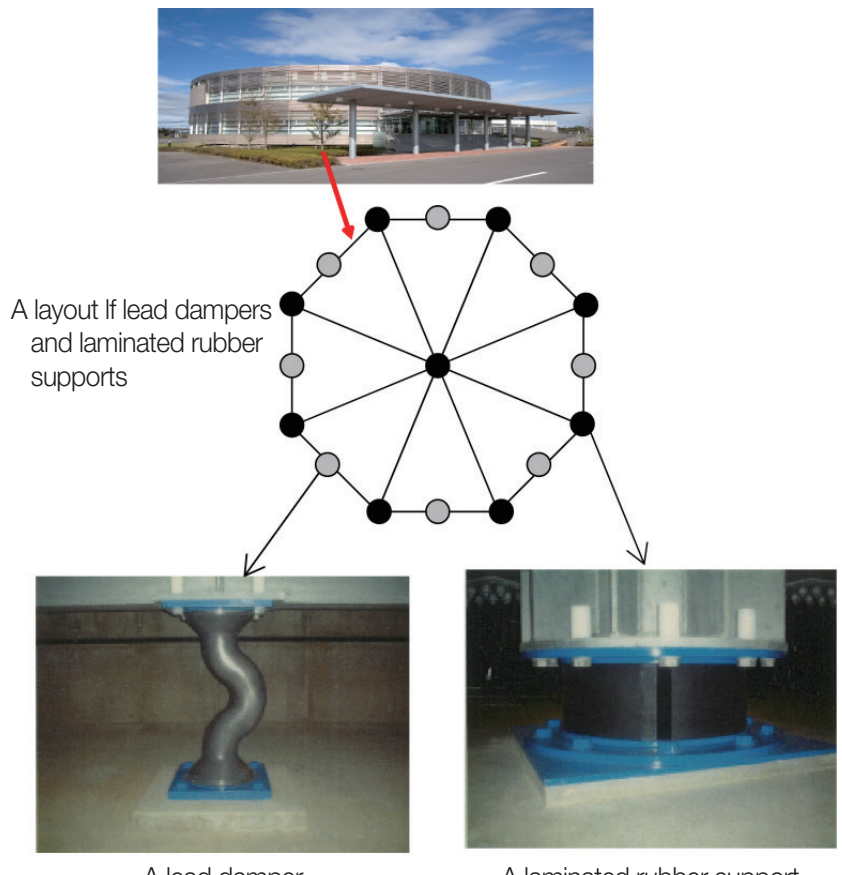

A lead damper

A laminated rubber support

Fig. 2. Quake-absorbing structure of Emergency Assistance Building of the Nuclear Emergency Assistance and Training Center. that will be induced by an earthquake. Consequently, the quake-absorbing structure of the Emergency Assistance Building helps protect the building and any equipment inside against severe earthquakes. Fig. 2 shows photos of the Emergency Assistance Building (NEAT-Ibaraki), a lead damper, a laminated rubber support, and a layout of eight lead dampers and nine laminated rubber supports.

\section{2) Emergency power supply}

To prepare for any potential power supply interruption, the NEAT-Ibaraki has installed an uninterruptible power supply system that will provide backup power for 10 minutes, and two power generators (500 kVA and $300 \mathrm{kVA}$ ). The $500 \mathrm{kVA}$ generator has enough power for a typical household, whereas the $300 \mathrm{kVA}$ generator can power the maintenance of the facilities in the building (Fig. 3). Once a month, a start-up test of these generators is performed in the NEAT.

\section{Installations}

1) Information sharing system

The NEAT has developed an information sharing system named Emergency information ClearingHOuse for emergency collaboration (ECHO) and installed it in the center; some local governments have also utilized it in their emer-

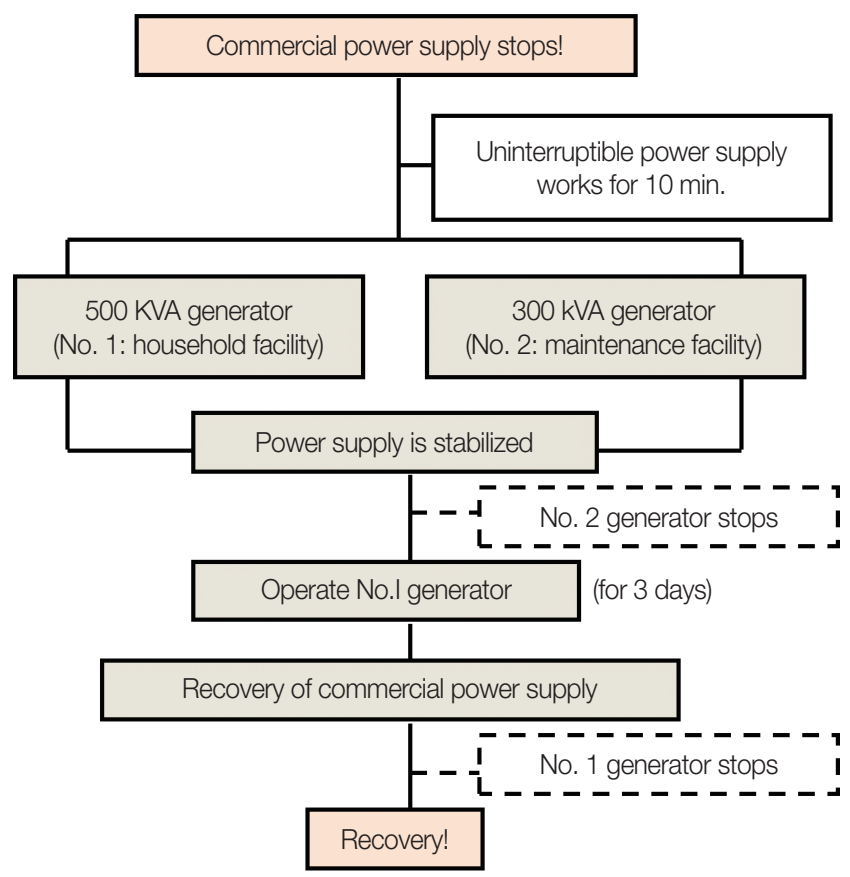

Fig. 3. Emergency power supply system of the Nuclear Emergency Assistance and Training Center. 


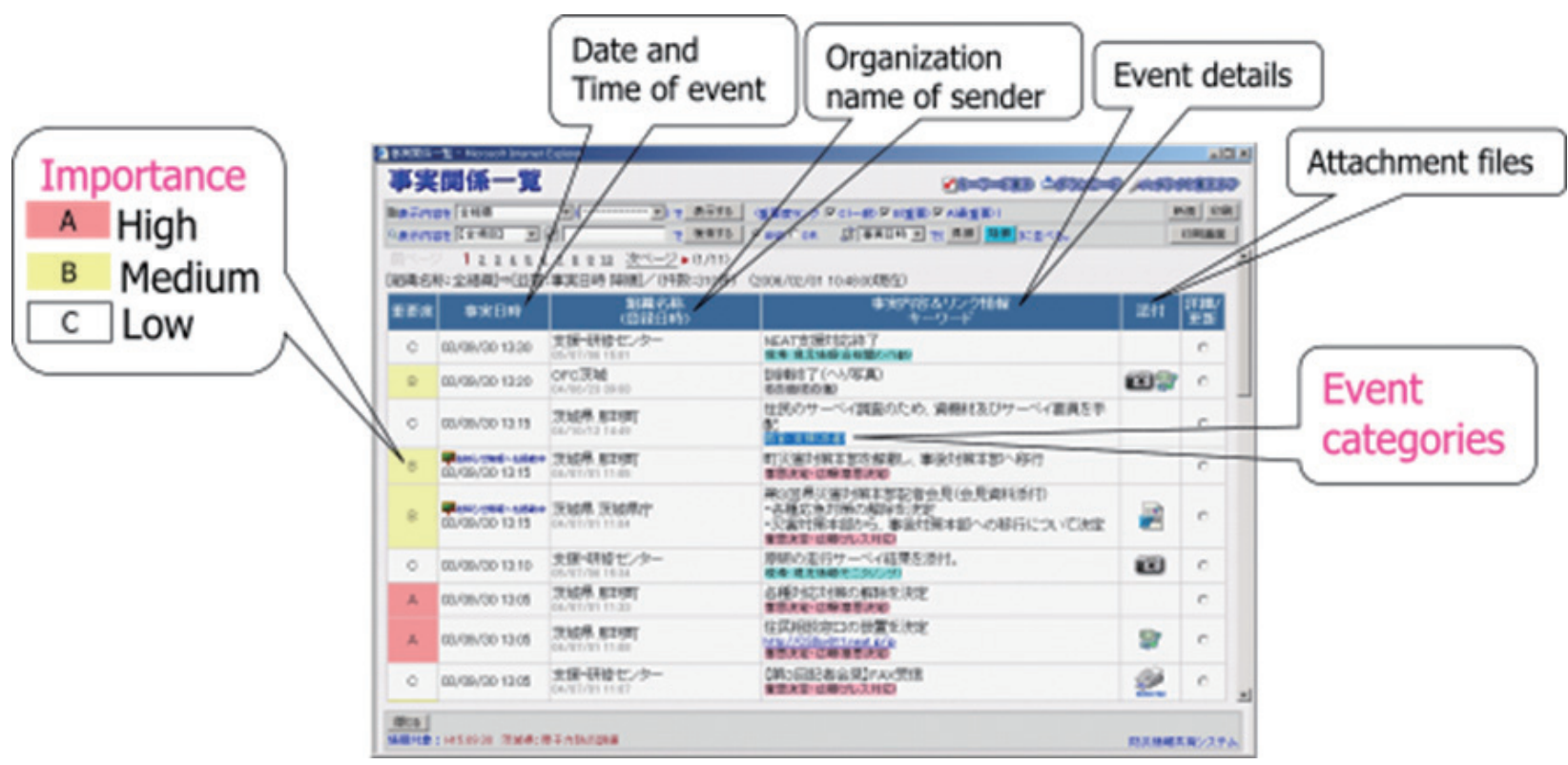

Fig. 4. A computer display panel of the information sharing system, named Emergency information ClearingHOuse for emergency collaboration (ECHO).

gency response training [3] (see also Yamamoto K. The information sharing for nuclear emergency in Japan. https:// ansn.iaea.org/Common/Topics/OpenTopic.aspx?ID = 9884).

ECHO has three functions: prioritizing events, showing the timelines of events, and recording and browsing events. These functions of ECHO facilitate information sharing among relevant persons responding to an emergency. Fig. 4 gives an example of the ECHO display. By utilizing ECHO, the JAEA shares information about nuclear emergency response with relevant responders in the NEAT. ECHO also helps record response information.

\section{2) Telephone consultation system}

When a nuclear disaster occurs, residents will ask the central/local governments various questions. The JAEA will assist them by answering questions on radiation safety. For this purpose, the JAEA has established a telephone consultation system, which is depicted in Fig. 5. Responses through this telephone consultation system to the Fukushima Daiichi accident will be described in Results and Discussion section (6.2 Radiation helplines operated at NEAT).

\section{3) Special vehicles}

During a nuclear emergency, the JAEA will need to lend special equipment to support the disaster response activities at local sites. The NEAT deployed the following special vehicles during the Great East Japan Earthquake: two body sur-

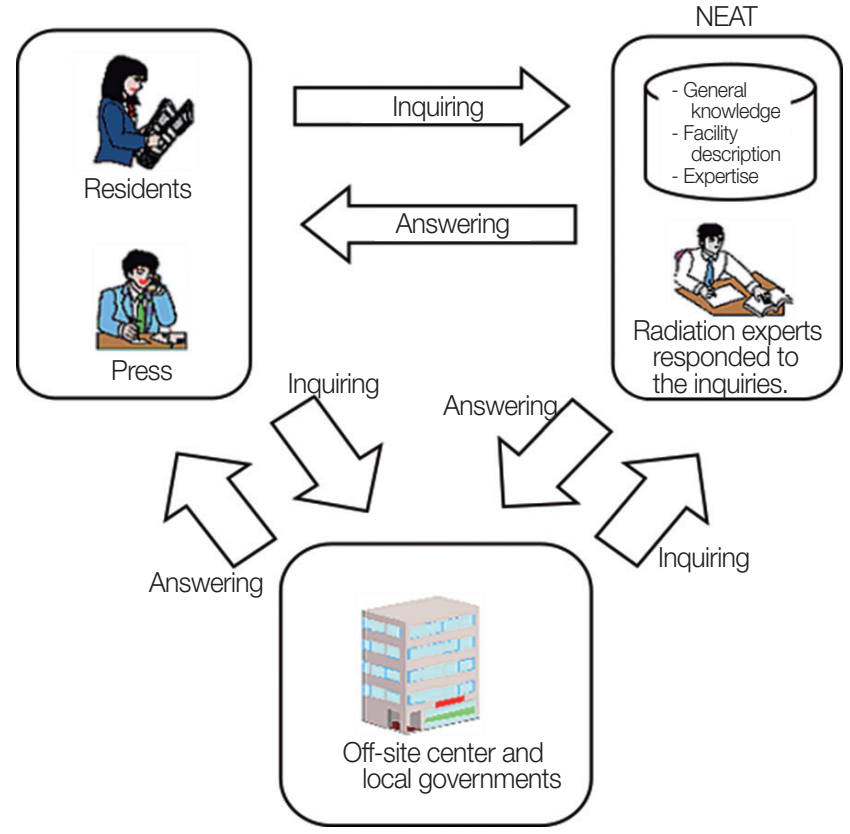

Fig. 5. Telephone consultation system. NEAT, Nuclear Emergency Assistance and Training Center.

face contamination monitoring vehicles, two whole-body counter (WBC) vehicles, a decontamination vehicle, two environmental monitoring vehicles, two command vehicles, and an equipment carrier. Dispatching the special vehicles to Fukushima will be described in Results and Discussion section (4. Dispatched Special Vehicles). 


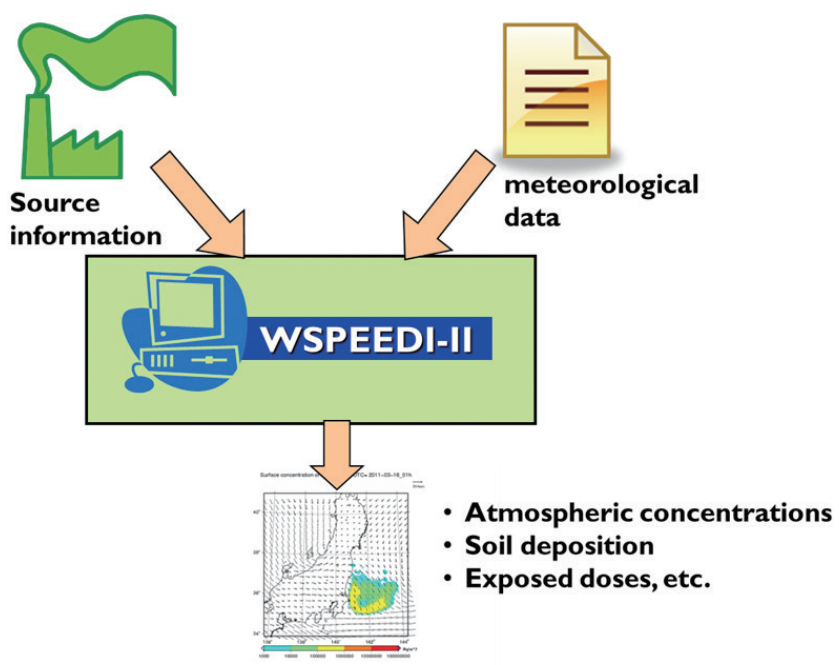

Fig. 6. Worldwide version of System for Prediction of Environmental Emergency Dose Information (WSPEEDI $2^{\text {nd }}$ version [WSPEEDI-II]) calculation.

4) Worldwide version of System for Prediction of Environmental Emergency Dose Information (second version) (WSPEEDI-II)

The NEAT has installed the WSPEEDI-II calculation system (Fig. 6) for calculating the worldwide dispersion of radioactive materials in order to respond promptly to any request for such calculation in an emergency. The installation had just finished before the accident occurred on March 11, 2011. The WSPEEDI-II calculation for the Fukushima Daiichi accident will be described in Results and Discussion section (7. Dispersion Calculation of Radioactive Materials with the WSPEEDI-II).

\section{Training and Exercises}

The NEAT organized training and exercises for the dedicated staff members of the center and the designated experts of the JAEA.

\section{1) Training for new staff members and experts}

The NEAT organized a one-day training course once every year for both newcomers and existing staff members of the center and the designated experts of the JAEA. The course included an introduction to emergency preparedness, the response frameworks of the national government and the JAEA, and the disaster management plan of the JAEA.

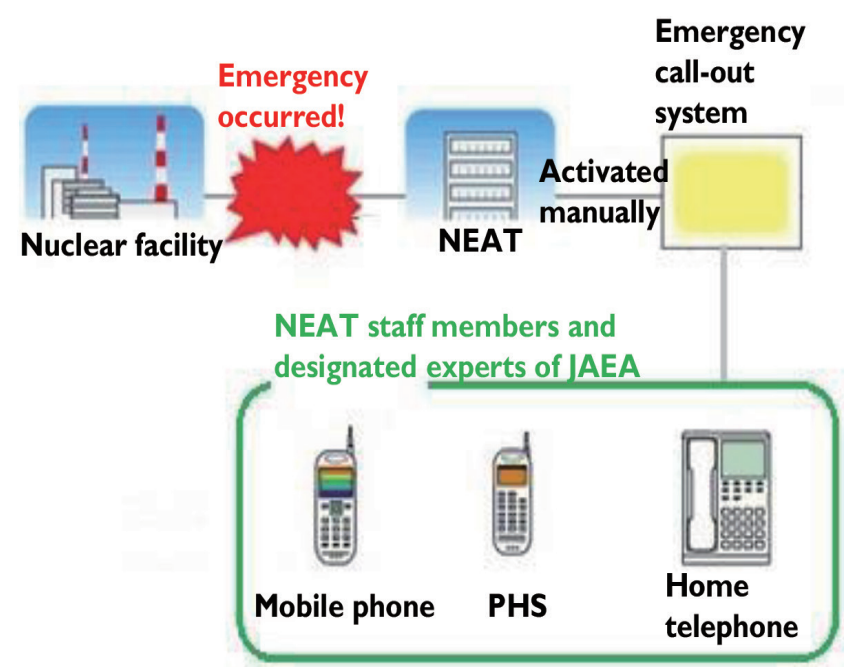

Fig. 7. Emergency call-out system. NEAT, Nuclear Emergency Assistance and Training Center; JAEA, Japan Atomic Energy Agency; $\mathrm{PHS}$, personal handy-phone system.

2) Training for new drivers of JAEA's official cars

The JAEA employed drivers for the agency's official cars, including the special vehicles mentioned in Materials and Methods section (3.3 Special vehicles). For all the drivers of the JAEA in the Ibaraki and Fukui regions, the NEAT organized a half-day training course that covers basic knowledge about radiation and protection measures.

This training proved helpful in dispatching the experts and the special vehicles of the JAEA to Fukushima during the response to the Fukushima Daiichi accident.

\section{3) NEAT exercises}

Before the Fukushima Daiichi accident, the NEAT occasionally conducted an exercise involving the NEAT staff members and the designated experts of the JAEA to reinforce their abilities. The last exercise was performed on December 15, 2010, wherein the participants were not informed about the scenario beforehand.

The flow of the exercise was as follows. Upon receiving notice from relevant organizations and requests for assistance from the Ministry of Education, Culture, Sports, Science and Technology (MEXT), the JAEA decided to dispatch JAEA staff to an off-site monitoring center in Okuma Town; performed technical support exercises at the NEAT for environmental radiation monitoring and evacuation of residents; exercises for dispatching experts and special vehicles and providing equipment were made just on table top [4]. 
4) Emergency notification drills

Emergency notification drills were organized and accomplished by the NEAT once a month. In each drill, the shift supervisor simultaneously called the NEAT staff members and the designated experts through an emergency call-out system, and each person called out was supposed to call back (Fig. 7).

5) Participation in nuclear emergency drills of the national and/or local governments

The NEAT participated in nuclear emergency exercises conducted by the national/local governments, and supported them technically, especially the following items [5]: dispatching experts, providing emergency equipment and materials, and dispatching special vehicles.

\section{Results and Discussion}

\section{Early Situation and Response}

At 14:46 on March 11, 2011, Japan experienced a strong earthquake that is now known as the 2011 Tohoku earthquake and tsunami.

At 14:47 (1 minute after the earthquake began, the NEAT activated its emergency response plan. This plan was established in accordance with the Heisei 16 Niigata Prefecture
Chuetsu Earthquake, which occurred in 2004. It was designed to be activated if a large-scale earthquake occurs or a tsunami warning is issued in a prefecture that houses a nuclear facility.

The safety of the NEAT staff members was confirmed, and damages to NEAT facilities were checked. The facilities and equipment of the center avoided excessive damage by the earthquake due to the quake-absorbing structure installed under the Emergency Assistance Building (see Materials and Methods section, 2.1 Quake-absorbing structure). Minor damages were observed in some ceiling panels in the garage for special vehicles. By contrast, the headquarters building of the JAEA (Tokai Village) was damaged by the earthquake, and there were difficulties in normal operation in the building.

Commercial power supply at the NEAT-Ibaraki, which is in Hitachinaka City, was halted for two days. The emergency generators started automatically; therefore, the activities of the center were not affected by the interruption in commercial power supply. However, there were difficulties in procuring the diesel fuel for the several days of operation of the power generators-a situation that was not anticipated before the earthquake.

\section{Collection of Information}

For the first several hours, the NEAT collected information

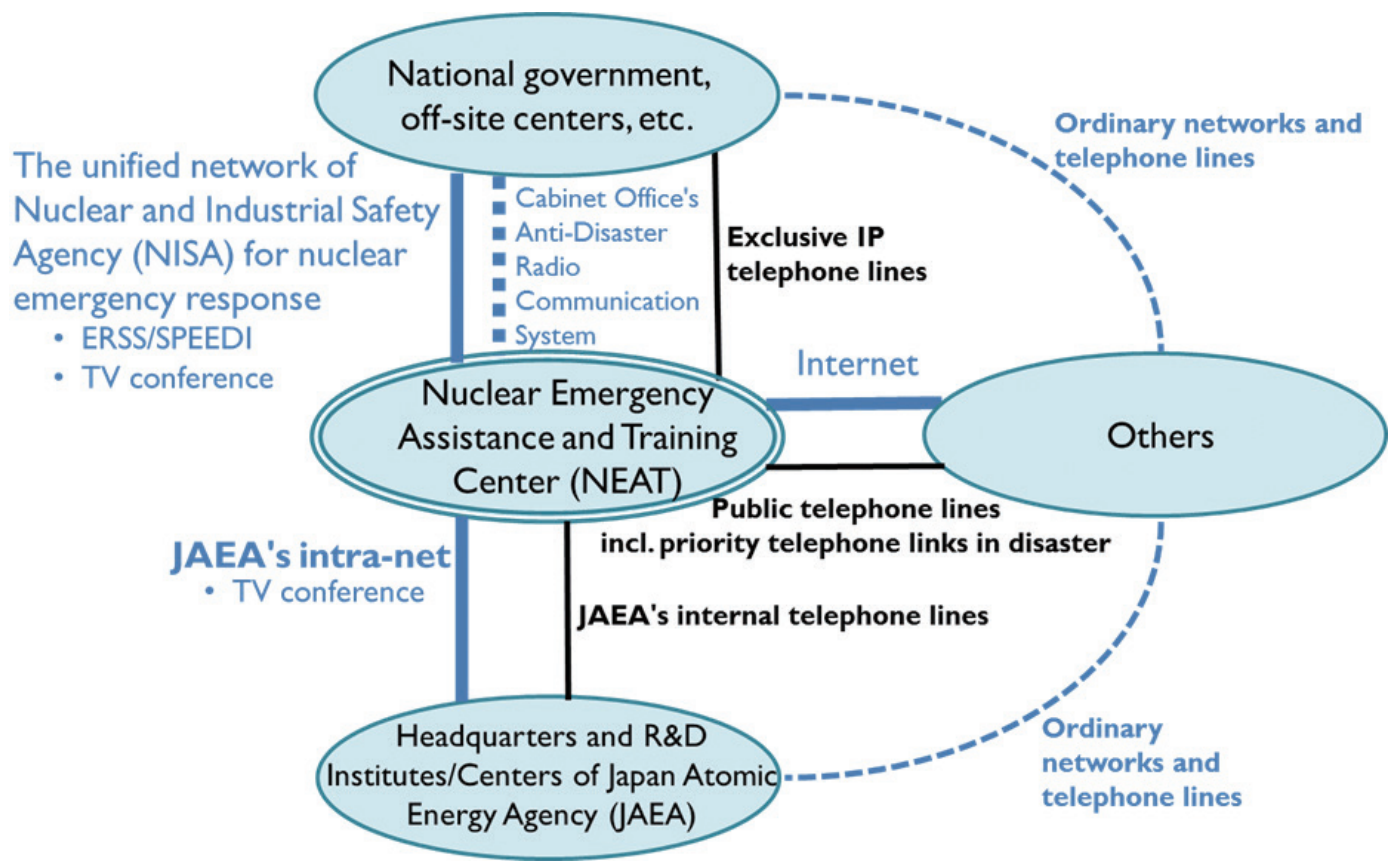

Fig. 8. The network of the Nuclear Emergency Assistance and Training Center of the Japan Atomic Energy Agency. ERSS, Emergency Response Support System; SPEEDI, System for Prediction of Environmental Emergency Dose Information. 
from various sources, such as facsimiles from nuclear facilities, commercial TV news and TV conferences, through the unified network of the Nuclear and Industry Safety Agency (NISA) for nuclear emergency response. The public telephone lines were busy, but the NEAT had four priority telephone lines, which helped in communication through public telephone lines during the disaster.

Fig. 8 outlines the information network for the NEAT. Despite the large-scale earthquake that occurred on March 11, 2011, some of the lines in the information network remained available at the NEAT, which thus avoided isolation.

Amid the response activities of the NEAT to the Fukushima Daiichi accident, ECHO (see Results and Discussion section, 1. Early Situation and Response) was very helpful in sharing relevant information and recording the response of the NEAT to the nuclear emergency.

\section{Environmental Radiation Monitoring and \\ Contamination Screening (by Radiation and Medical Squads)}

By the request of the MEXT, which was received at 22:46 on March 11, 2011, the JAEA dispatched seven experts on environmental radiation monitoring to the environmental radioactivity monitoring center of Fukushima, which was located next to the Fukushima off-site center in Okuma Town. They left the NEAT at 1:54 on March 12, 2011, and arrived at the monitoring center at 6:30.

The first JAEA team was transported by a helicopter of the Japan Self-Defense Forces. The second and following JAEA teams were transferred from Ibaraki Prefecture to Fukushima Prefecture on a JAEA bus and other vehicles. The first and second JAEA teams were based in the monitoring center; they measured the environmental air dose rates and collected dust samples $10 \mathrm{~km}$ north of both centers for iodine measurement in cooperation with the MEXT, Fukushima prefectural government, and other relevant organizations [6].

On the night of March 14, 2011, a decision was made to relocate the local nuclear emergency response headquarters at the off-site center in Okuma Town to the prefectural office building in Fukushima City [7]. The first and second JAEA teams of the JAEA returned to Ibaraki Prefecture. The third and following JAEA teams were dispatched to the alternative off-site center in Fukushima City. The fifth and following JAEA teams left every two days and stayed in Fukushima Prefecture for five days. The JAEA divided its dispatched teams into a radiation support group and a medical support group. The odd-numbered JAEA teams executed environmental radiation monitoring in cooperation with the MEXT as members of the radiation support group, and the evennumbered JAEA teams prepared for emergency medical activities at the Fukushima Medical University as members of the medical support group. From June 2011, both even- and odd-numbered JAEA teams worked as members of the radiation support group.

The radiation support group measured the environmental radiation with a monitoring vehicle and measured the concentrations of radioactive materials in the soil and air every day outside the 20-km-radius from TEPCO's Fukushima Daiichi NPS. Occasionally, by the request of Fukushima Prefecture, the group also measured environmental radiation in schoolyards to monitor the environment of pupils and junior high-school students before classes resumed. The MEXT summarized the measured and analyzed results of the JAEA and other organizations; they were disseminated to the public through the MEXT website (later, the results were transferred to the website of the Nuclear Regulation Authority after a reorganization of agencies related to nuclear regulation; Reading of Land Monitoring, https://radioactivity.nsr.go.jp/ en/list/313/list-1.html).

\section{Dispatched Special Vehicles}

The NEAT, which is headquartered in Ibaraki Prefecture and has a branch in Fukui Prefecture, owned special vehicles (see Materials and Methods section, 3.3 Special vehicles). The vehicles of the Fukui branch of the NEAT were moved to the NEAT-Ibaraki before being dispatched to Fukushima. The dispatched vehicles are shown in Fig. 9. The figure includes a WBC vehicle of the Nuclear Fuel Cycle Engineering Laboratories of the JAEA.

The medical support group of the JAEA deployed two special vehicles to Fukushima Medical University: a vehicle mounted with four shower facilities and a vehicle mounted with two body surface counters. They were deployed to prepare for a contamination check of many local residents, which might be performed in the case of another massive release of radiological materials from the Fukushima Daiichi NPS.

Subsequently, two WBC vehicles were lent to TEPCO, and they were actively utilized to measure the internal radiation doses of TEPCO's emergency workers. One WBC vehicle was used at Onahama, Iwaki City, as a substitute for the fixed-type on-site WBCs of the Fukushima Daiichi NPS, which were un- 


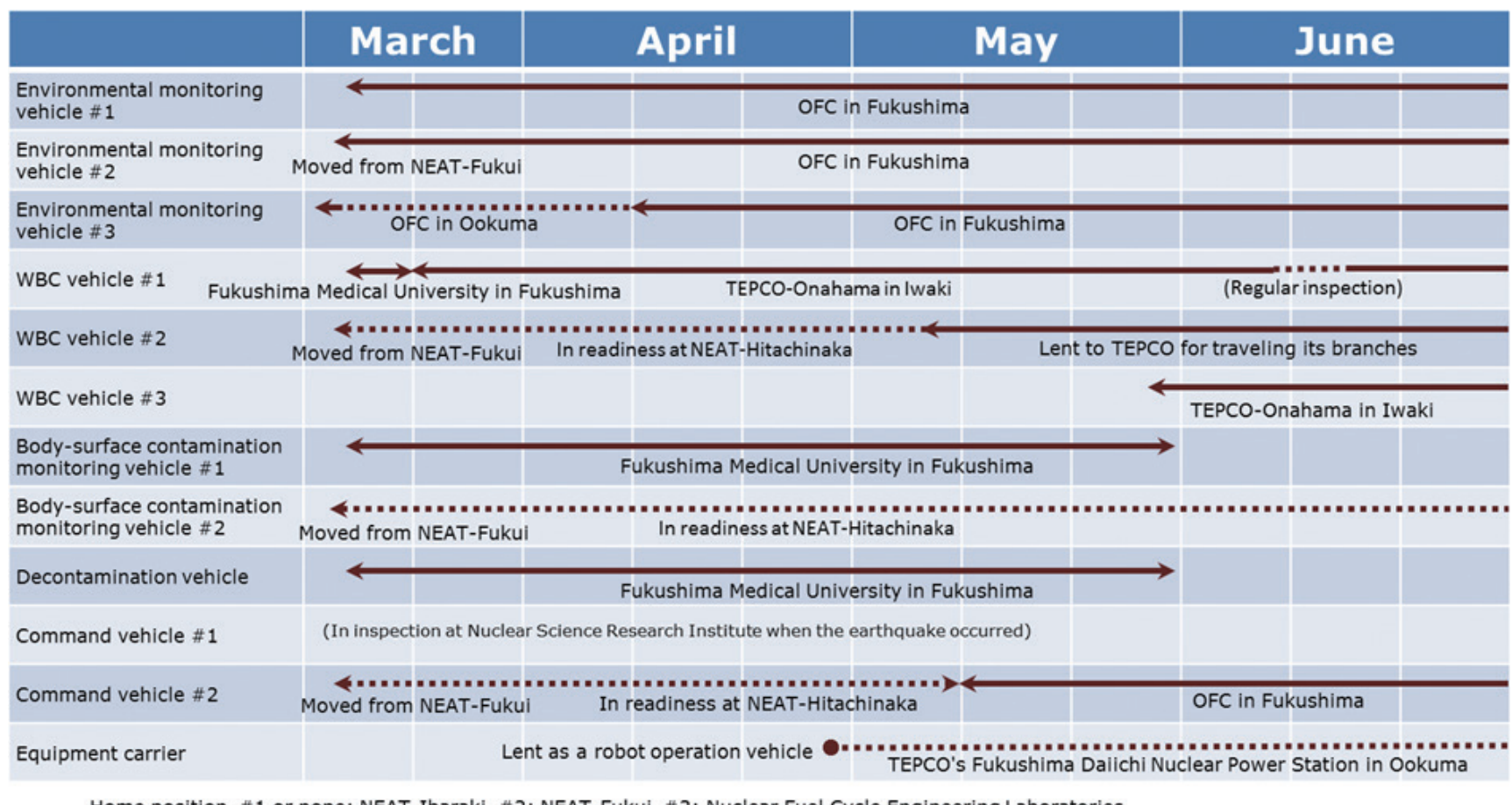

Home position \#1 or none: NEAT-Ibaraki, \# 2: NEAT-Fukui, \# 3: Nuclear Fuel Cycle Engineering Laboratories

Fig. 9. Vehicles dispatched from the Japan Atomic Energy Agency to Fukushima. WBC, whole-body counter; OFC, Off-cite Center; NEAT, Nuclear Emergency Assistance and Training Center; TEPCO, Tokyo Electric Power Company.

available under the high-radiation background. The other WBC vehicle was used at TEPCO's branches for measuring the internal doses of its workers. The dose evaluation was performed by the JAEA experts for the data from the start until the data measured on May 12, 2011.

The body surface contamination monitoring and decontamination vehicles at Fukushima Medical University were returned to the NEAT-Ibaraki, and the associated staff started assisting the radiation squad.

A vehicle was dispatched to the alternative off-site center in Fukushima City from May 10 and July 9 [8]. The equipment carrier was lent to the emergency response headquarters of the JAEA, which was later succeeded by the Headquarters of Fukushima Partnership Operations. It was used as a carrier of robots that were intended to support technically diverse on-site activities.

\section{JAEA's Equipment Offered to Other Organizations}

The survey meters and personal dosimeters of the JAEA were primarily for the use of JAEA personnel. However, some of them were lent to the national government, local governments, and TEPCO to strengthen their capabilities to measure radioactivity. The major borrowers are listed in Table 1.
Table 1. Radiation Measurement Equipment Lent out from the Japan Atomic Energy Agency

\begin{tabular}{lrl}
\hline $\begin{array}{l}\text { Radiation measurement } \\
\text { equipment }\end{array}$ & Quantities & \multicolumn{1}{c}{ Borrower } \\
\hline $\begin{array}{l}\text { lonization chamber } \\
\text { Teletector }\end{array}$ & $\leq 62$ & Tokyo Electric Power Company \\
Gamma camera & 1 & $\begin{array}{l}\text { Tokyo Electric Power Company } \\
\text { Geiger Mueller }\end{array}$ \\
Nal(TI) scintillation & 10 & $\begin{array}{l}\text { Local nuclear emergency } \\
\text { response headquarters }\end{array}$ \\
& Several & $\begin{array}{l}\text { Local governments } \\
\text { Ministry of Economy, Trade and } \\
\text { Industry }\end{array}$ \\
\hline
\end{tabular}

Additional details from March 2012 are available in [8].

\section{Telephone Consultation}

1) Radiation helplines operated in Fukushima Prefecture

By the request of the Ministry of Economy, Trade and Industry (METI), the JAEA dispatched two experts in turn to a government office of Fukushima Prefecture from the start of the telephone inquiry services on March 18, 2011, mainly for the residents of Fukushima Prefecture. With information from news reports and their background knowledge and experiences, they responded to the questions of the residents, which were mainly about technical issues, in cooperation 


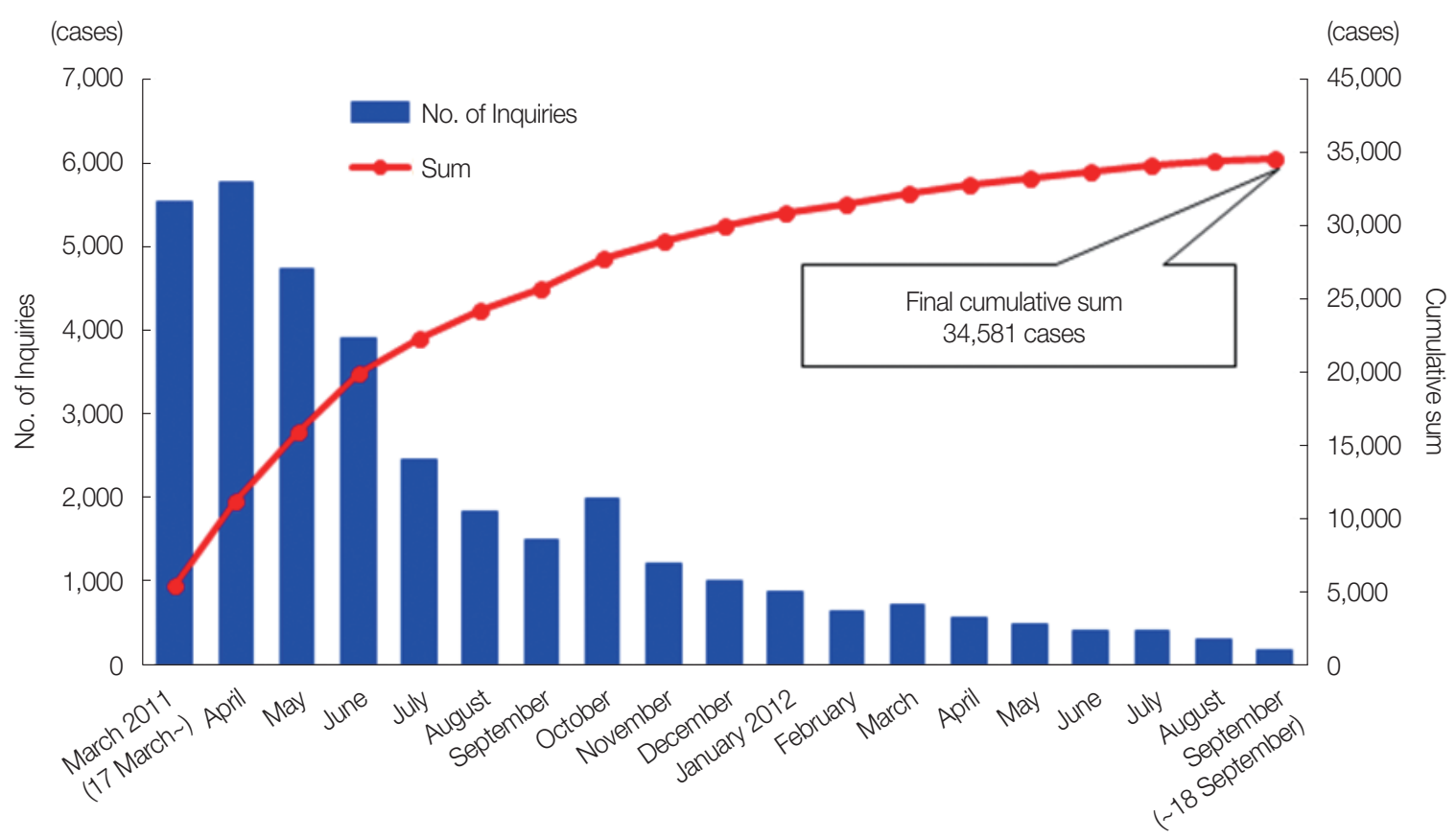

Fig. 10. The number of inquiries received through helplines opened at the Nuclear Emergency Assistance and Training Center of the Japan Atomic Energy Agency.

with prefectural officers.

The telephone consultation services were open for 24 hours during the early months. The JAEA dispatched two additional experts, i.e., four experts for each day from March 26, 2011 to April 29, 2011, and they played a crucial role in the telephone responses. The operation time was reduced to 8:0021:00 beginning April 30, 2011. The dispatch of JAEA experts continued until August 8, 2011. On the next day, a new onestop service was initiated in Fukushima City by a contract of the METI/NISA.

\section{2) Radiation helplines operated at NEAT}

By the request of the MEXT, the JAEA opened radiation helplines to respond to the questions of the public about the health effects of the Fukushima Daiichi accident. The experts of the JAEA answered their inquiries on radioactivity and radiation and addressed their fears of the effect of radiation on health. The consultation services of the JAEA for the residents, who felt fear in daily life, continued for almost a year and a half (March 17, 2011 to September 18, 2012). Other radiation helplines, as requested by the MEXT, were operated by the National Institute of Radiological Sciences (NIRS) and universities, such as the University of Tokyo and Kindai University.

The helplines were operated at the NEAT in collaboration

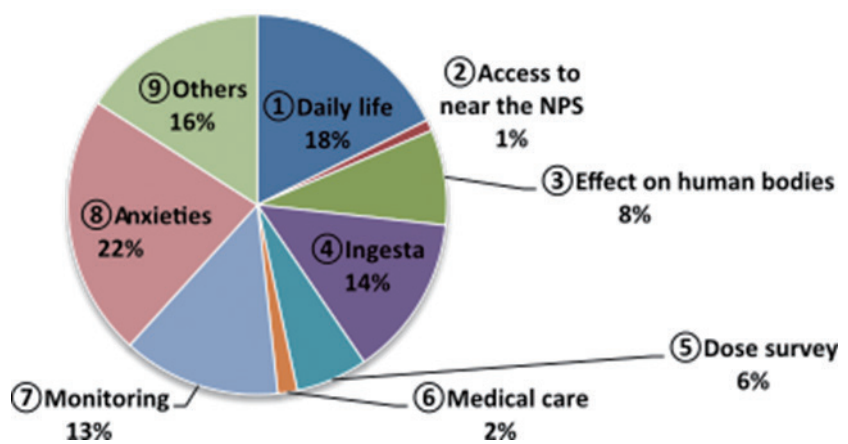

Fig. 11. Categories and their percentages of inquiries received at the Nuclear Emergency Assistance and Training Center of the Japan Atomic Energy Agency. NPS, nuclear power station.

with major branches of the JAEA. Overall, 5,618 responders attended to a total of 34,581 inquiries. As shown in Fig. 10, the number of inquiries per month amounted to more than 5,000 in March and April 2011. It decreased gradually to 2,000 in August; 1,000 in January 2012; and less than 500 in May 2012 onward. Fig. 10 shows a graph depicting the number of inquiries received by the radiation helplines at the NEAT each month.

The issues discussed through the helplines covered a wide variety of fields, such as daily life, food and drink to consume, fears or worries, environmental monitoring, dose measurements, and requirements to the central and local governments 
and compensation. The main categories were fear $(22 \%)$, daily life (18\%), and ingesta (14\%), as shown in Fig. 11.

\section{Dispersion Calculation of Radioactive Materials with WSPEEDI-II}

The MEXT employed the System for Prediction of Environmental Emergency Dose Information (SPEEDI) for training and exercises for nuclear emergency response in Japan.

In the early morning of March 15, 2011, the MEXT asked the JAEA to use WSPEEDI-II to predict the dispersion of radioactive materials within a wider range than $100 \mathrm{~km}$, which is the maximum limit for SPEEDI calculations.

WSPEEDI, a worldwide version of SPEEDI, was developed by the Nuclear Science and Engineering Branch of the JAEA. The second version of WSPEEDI, WSPEEDI-II, was completed in 2009. However, the WSPEEDI-II system of the offices of Nuclear Science and Engineering Branch, which was originally designed for research and installed at the agency's Tokai site, could not be operated because the site was blacked out. The JAEA therefore performed the calculation at the NEAT, where WSPEEDI-II had been installed as backup in early 2011 in case of emergency at the system at the Tōkai site.

The JAEA reported the first result to the MEXT around noon on the same day of the request. The MEXT sent another request in the afternoon (source estimation calculation); the JAEA performed the calculation and reported the result on the same day.

The calculation at the NEAT continued until May 12, 2011. The results were reported to the Nuclear Safety Commission

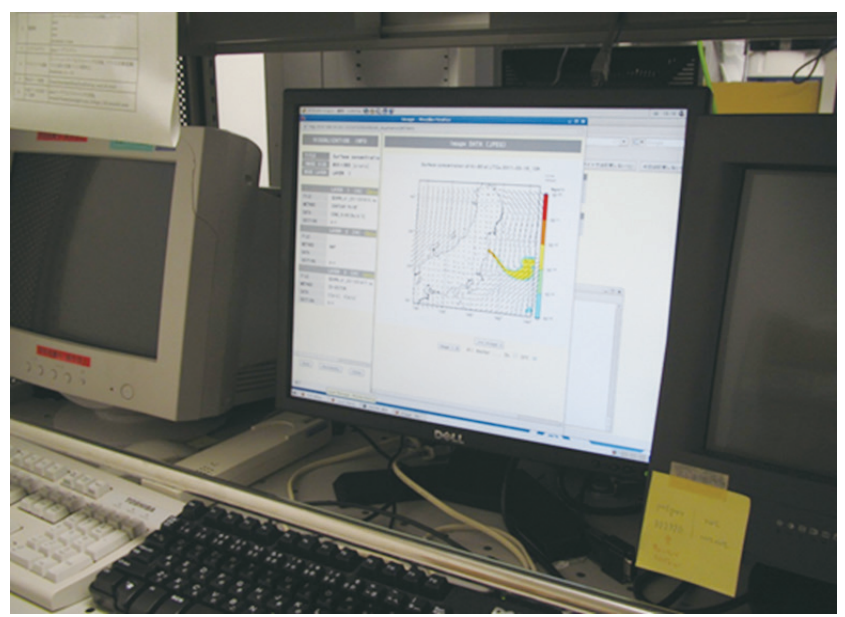

Fig. 12. A result of Worldwide version of System for Prediction of Environmental Emergency Dose Information (WSPEEDI $2^{\text {nd }}$ version [WSPEEDI-II]) calculated at the Nuclear Emergency Assistance and Training Center of the Japan Atomic Energy Agency.
(NSC) of Japan and the MEXT from March 16 to April 8 upon their requests (Fig. 12).

In addition to the abovementioned calculations, the Nuclear Science and Engineering Center, JAEA, generated prediction calculations with an assumed release time and rates after the commercial electric power resumed; the results were released from the MEXT. Another calculation that the JAEA performed was the iodine deposition concentration on the ground, which was requested by Ibaraki Prefecture on March 20, 2011; the results were submitted to the prefecture.

\section{Time Sequence of Personnel Arrangement at NEAT}

The JAEA's emergency management plan did not cover long-time engagement in nuclear emergency response before the Fukushima Daiichi accident. The following is the time sequence of personnel arrangement that the NEAT eventually adopted.

(1) From March 11 to March 15: All NEAT staff members responded to the emergency situation. Breaks were taken alternately, including trips home.

(2) From March 16 to March 31: All NEAT staff members were grouped into two shifts:

- Day shift: from 9:00 to 21:00

- Night shift: from 21:00 to 9:00 the next day

(3) From April 1 to May 31: Four groups were established by some of the NEAT staff members and supporters from other establishments. The following shifts were operated by the four groups:

- Shift 1: from 9:00 to 17:30

- Shift 2: from 17:20 to 21:10

- Shift 3: from 21:00 to 9:10 the next day

- Shift 4: free

(4) From June 1 to September 30: Six groups were formed, and they worked in the six shifts indicated below. Each group consisted of a supervisor and a manager from NEAT and two staff members from other establishments. The operation time was from 8:00 to 22:00.

- Shift 1: from 8:00 to 16:30

- Shift 2: from 13:30 to 22:00

- Shifts 3-6: free

(5) From October 1 to December 25: The operation and shift times remained the same as above, but only some of the NEAT staff members worked.

The environmental radiation monitoring activities that the JAEA undertook were initially managed by the NEAT, but the headquarters of Fukushima Partnership Operations gradu- 
ally took over, as discussed in the next section. Therefore, most of the emergency response activities of the JAEA at the NEAT ceased at the end of 2011; the only activities that continued were the dispatch of a NEAT staff member to the offsite center in Fukushima City (until October 31, 2012) and the telephone consultation (until September 18, 2012).

\section{Radiation Exposure Management in Response to Fukushima}

For radiation exposure control during the support activities, the effective dose was limited to $10 \mathrm{mSv}$, which is $1 / 10$ of the $100 \mathrm{mSv}$ exposure limit for workers in an emergency; $5 \mathrm{mSv}$, which is $1 / 2$ of the limit, was set as the standard for radiation exposure control. However, both the exposure limit and the exposure control standards were raised temporarily by 2.5 times during March 17 and December 16, 2011, by the Ministry of Health, Labour and Welfare.

\section{Others}

The JAEA cooperated with the national government, especially the NSC and the MEXT. The experts dispatched by the agency to the NSC contributed technological studies in the fields of diffusion evaluation analysis and radiation management. The experts deployed to the Emergency Operation Center (EOC), MEXT, summarized environmental radiation and radioactivity data on 24-hour schedules.

The JAEA established the Headquarters of Fukushima Partnership Operations on May 6, 2011, to provide technical support in the medium- and long-term technical restoration following the nuclear accident at the Fukushima Daiichi NPS, and to strengthen the structure in response to the accident (https://www.jaea.go.jp/english/jishin/kiji/press110502.pdf).

\section{Discussion}

This section mentions certain issues regarding the emergency response activities that the JAEA actually experienced or might experience in the future.

\section{1) Vulnerability of a response organization to a disaster}

In the traditional concept of nuclear emergency preparedness and response, a response organization offers help to disaster victims with pre-assumed response systems. However, the JAEA, which is designated as a response organization against nuclear disasters, suffered damages in some of its building and its facilities at its various sites in Ibaraki Prefecture caused by the Great East Japan Earthquake and associ- ated incidents, including the tsunami. Basic infrastructure, including electricity, water, and gas, was interrupted, and some roads and bridges were destroyed. The JAEA had to address a difficult situation $[9,10]$ (situation and response of the JAEA to the Great East Japan Earthquake: https://www. jaea.go.jp/eng- lish/jishin/past.html).

In the nuclear response system, the intactness of the response system was implicitly assumed. However, given the situation of the JAEA during the Great East Japan Earthquake, the response organization and system should be designed to work despite damage.

The Part XII "Nuclear Disaster Countermeasures" of the Basic Disaster Management Plan (http://www.bousai.go.jp/ taisaku/keikaku/pdf/kihon_basic_plan160216.pdf) introduces a new section describing preparedness for complex natural and nuclear disasters. It considers a harmonization between responses to natural disasters and nuclear disasters; however, it does not assume that the response organizations themselves would suffer damages.

The main building of the NEAT (NEAT-Ibaraki) had a quake-absorbing structure. It also had an alternative power system and emergency priority telephone lines. These measures helped in its emergency response activities. However, the NEAT encountered difficulties due to the lack of an alternative water supply and food for emergency responders. Following the Great East Japan Earthquake, the NEAT dug a well at its site and has started storing food inside the building to prepare for water and food shortages.

\section{2) Preparation for long-term response}

(1) Designated experts of JAEA

As mentioned in Materials and Methods section, the JAEA had the Disaster Management Operation Plan, which establishes a system of designated experts. However, during the response to the Fukushima Daiichi accident, the experts dispatched to Fukushima were not necessarily those who were designated beforehand. For examples, seven experts in environmental monitoring were dispatched from the JAEA to the monitoring center in Okuma Town. The leader was a NEAT staff member, and one of the dispatched members was a designated expert in environmental monitoring. The five other dispatched experts were not previously designated ones. Nonetheless, this situation does not necessarily mean that the Disaster Management Operation Plan was ineffective. Because of the plan, the JAEA smoothly deployed its experts to Fukushima for environmental monitoring despite 


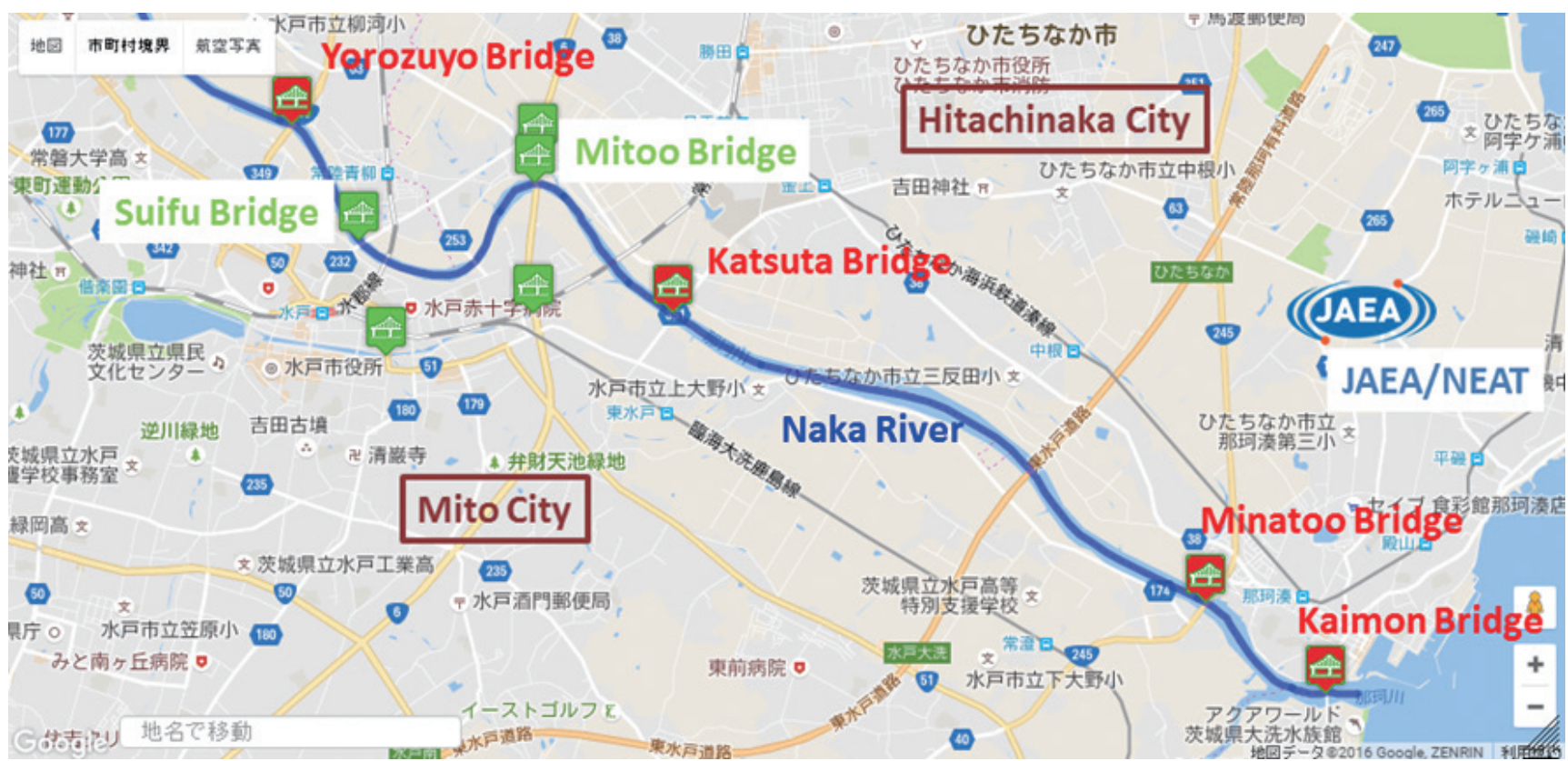

Fig. 13. Bridges that could not pass over soon after the Great East Japan Earthquake (red colored; the green-colored bridges were open). It was drawn by utilizing the site at http://river.longseller.org/rc/8303020001.html. JAEANEAT, Nuclear Emergency Assistance and Training Center of the Japan Atomic Energy Agency.

the heavy damage at its Ibaraki Prefecture site. The JAEA dispatched its experts at 1:54 on March 12, 2011, which was almost three hours after it received the request from the MEXT.

\section{(2) Replacement}

Before the Fukushima Daiichi accident, replacement of response staff was not considered. This was probably because the JAEA had not undertaken any long-term nuclear emergency response.

However, the response to the Fukushima Daiichi accident consumed a long-time, i.e., more than the few days that were initially assumed. Therefore, the JAEA had to consider replacement of response staff.

The JAEA's Disaster Management Operation Plan, which was revised after the Fukushima Daiichi accident, states the following in Chapter 3 (Disaster Prevention [Proactive Measures against a Disaster]) about considering the replacement of response staff: "The staff mobilization plan should consider an emergency situation continuing long."

(3) Consideration of emergencies that may occur in another time or place

The large-scale earthquake that triggered the Fukushima Daiichi accident occurred during the working hours of the JAEA. The NEAT started to mobilize a minute after the earth- quake started. However, an earthquake may occur at any time, and the initial response would be considerably different from the Fukushima Daiichi case if the earthquake had occurred at night or during the weekend. For example, NEAT staff members who lived in Mito City could have encountered difficulties in traveling to the Emergency Assistance Building of the NEAT in Hitachinaka City, given that many bridges over the Naka River, which separates Mito and Hitachinaka, were damaged in this large earthquake (Fig. 13). Thus, the NEAT established a business continuity plan in 2015, after reviewing its response to the Fukushima Daiichi accident.

Another issue was the transportation of experts. Fukushima Prefecture lies to the north of Ibaraki Prefecture. Transportation between Hitachinaka City and Fukushima City by bus through highways consumed about four hours. Had the accident occurred in Kagoshima Prefecture (Sendai NPS) or Hokkaido (Tomari NPS), transportation would have been a major problem.

(4) Development and maintenance, including revision of technology for responding to nuclear/radiological emergencies

Response experiences should be published. A nuclear emergency accompanied by the evacuation of local resi- 
dents is a very rare event; therefore, the experiences of response organizations will considerably help the response organizations of other countries. One of the main purposes of this paper is to report some of the key elements of the experiences of the JAEA as a designated technical support organization in nuclear emergency response.

Institutions specializing in emergency response to nuclear/radiological emergencies are very rare. In Japan, two institutions specialize in emergency response to nuclear/radiological emergencies: the JAEA/NEAT and the NIRS (of the National Institutes for Quantum and Radiological Science and Technology [QST]). The QST/NIRS published a report in 2016 detailing its five-year activities in responding to the Fukushima emergency [11]; it also discussed its first response in a journal paper [12]. In addition, the NEAT published a report of its three-month activities [2], but it was not a journal paper.

The above lessons from these response activities show the importance and necessity of developing, modifying, and maintaining technologies intended for responding to nuclear/radiological emergencies. Finally, some of the efforts undertaken by the JAEA, including the telephone consultation at the NEAT [13] and the radiation monitoring of soils in Fukushima Prefecture [14], should be further examined in future work.

\section{Conclusion}

The JAEA is a nuclear research and development institute in Japan that employs many experts in radiation protection. As a designated public corporation, the JAEA technically supported the national government, Fukushima prefectural government, and Ibaraki prefectural government in responding to the off-site emergencies caused by the Fukushima Daiichi accident in March 2011. This paper outlines the early response of the NEAT (JAEA), which includes (1) collection of relevant information, (2) environmental radiation monitoring and contamination screening, (3) dispatch of special vehicles, (4) provision of equipment to other organizations, (5) telephone consultation on radiation contamination effects, and (6) technical support operated at the NEAT.

The NEAT had prepared for a general nuclear emergency and performed nuclear emergency drills. Some of the preparations made before the Fukushima Daiichi accident helped in the response to the emergency. They included the telephone consultation system installed at the NEAT, the desig- nated expert system of the JAEA, and the quake-absorbing structure of the Emergency Assistance Building, NEATIbaraki. With these preparations, the JAEA's response to the Fukushima emergency worked well.

Response organizations may also suffer from disasters. In fact, the JAEA incurred building and facility damage, lost power, and lost water due to the Great East Japan Earthquake. This paper elucidates this issue on the basis of the experiences of the JAEA.

The agency's experiences with the disaster response were valuable, as such events are rare and result in unhappy events among the local residents. Nonetheless, variations of source term variables from the Fukushima Daiichi accident should be examined in the future to utilize these exceptionally vital experiences with disaster response effectively.

\section{Conflict of Interest}

No potential conflict of interest relevant to this article was reported.

\section{Acknowledgements}

The authors acknowledge all the JAEA staff members who were engaged in the early responses of the JAEA to the nuclear emergencies associated with the TEPCO's Fukushima Daiichi NPS. The authors extend their appreciation to Dr. Kanamori and Mr. Katagiri, who were Director and Deputy Director of NEAT, respectively, and who led the responses of the JAEA in the emergency situation when the Great East Japan Earthquake occurred. The contributions of Mr. Muto and Mr. Watanabe in their notable commitment in their emergency responses in Fukushima Prefecture should be noted. The authors express their gratitude to Mr. Fukumoto and Mr. Kikuchi for their contributions in the logistics group of the NEAT. The authors thanks Ms. Nakanishi of Visible Information Center Inc., who was a staff member of NEAT at the time of Fukushima Daiichi NPS accident, for her permission to use WSPEEDI-II calculation diagram, which was cited as Fig. 6 in this paper. In preparing this paper, the first draft was checked by Mr. Usui of the former JAEA staff, to whom the authors mention his contribution.

\section{Author Contribution}

Conceptualization: Okuno H. Data curation: Sato S, Kawaka- 
mi T. Writing - original draft: Okuno H. Writing - review \& editing: Sato S, Kawakami T, Yamamoto K, Tanaka T. Investigation: Okuno H, Sato S, Yamamoto K. Supervision: Tanaka T. Validation: Kawakami T, Yamamoto K.

\section{References}

1. Watanabe F, Matsui T, Nomura T. Activities of the nuclear emergency assistance and training center: strengthening co-operation with parties in normal circumstances. Proceedings of International Conference on Nuclear Energy Systems for Future Generation and Global Sustainability; 2005 Oct 9-13; Tsukuba, Japan

2. Sato S, Yamamoto K, Muto S, Katagiri H, Fukumoto M. Lessons learned and recommendations according to nuclear disaster prevention based on the support activities to the accident at Fukushima Nuclear Power Stations (Report No. JAEA-Review-2011049). 2012. Tokai, Japan: Japan Atomic Energy Agency; 2012.

3. Watanabe F, Yamamoto K, Sajiki K, Yasu S, Igarashi M. Development of emergency information clearinghouse for nuclear emergency management (Report No. JAEA-TECHNOLOGY-2008-025). Tokai, Japan: Japan Atomic Energy Agency; 2008.

4. Katagiri H, Okuno H, Sawahata M, Ikeda T, Sato S, Terakado N, et al. Annual report of Nuclear Emergency Assistance and Training Center: April 1, 2010-March 31, 2011 (Report No. JAEA-REVIEW-2011-037). Tokai, Japan: Japan Atomic Energy Agency; 2011.

5. Okuno H, Okamoto A, Ebine N, Hayakawa T, Tanaka T. Preparedness and response for nuclear or radiological emergency as a designated public corporation. Proceedings of the International Conference on Nuclear Engineering (ICONE); 2019 May 19-24; Tsukuba, Japan.

6. Yamazawa H, Kimura H, Koyama Y, Iwasaki T. Sheltering or evacuation? Role of emergency monitoring in nuclear disaster control. J At Energy Soc Jpn. 2016;58:115-120.

7. Japan Nuclear Energy Safety Organization. Initial Operations in the local nuclear emergency response headquarters (Report No.
JNES-RE-2013-0002). Tokyo, Japan: Japan Nuclear Energy Safety Organization; 2013.

8. Katagiri H, Okuno H, Okamoto A, Ikeda T, Tamura K, Nagakura T, et al. Annual report of Nuclear Emergency Assistance and Training Center: April 1, 2011-March 31, 2012 (Report No. JAEA-REVIEW-2012-033). Tokai, Japan: Japan Atomic Energy Agency; 2012.

9. Ibaraki Shimbun Editorial Office. Verification of March 11: Great East Japan Earthquake. Mito, Japan: Ibaraki Shimbun Newspaper; 2012.

10. Yasuhara K, Tamura M, Tabayashi Y, Murakami S, Nakajima H. Residential damage in Ibaraki during the Great Eastern Japan Earthquake. Proceedings of the International Symposium on Engineering Lessons Learned from the 2011 Great East Japan Earthquake; 2012 Mar 1-2; Tokyo, Japan.

11. National Institute of Radiological Sciences. Response to the accident at TEPCO's Fukushima Daiichi Nuclear Power Station Activity record of the staff of the National Institute of Radiological Sciences (Report No. NIRS-M-286). Chiba, Japan: National Institute of Radiological Sciences; 2016.

12. Tominaga $T$, Hachiya $M$, Akashi M. Lessons learned from response to the accident at the TEPCO Fukushima Daiichi Nuclear Power Plant: from the viewpoint of radiation emergency medicine and combined disaster. Radiat Emer Med. 2012;1:56-61.

13. Usui $H$, Kobayashi $H$. The analysis of the contents of telephone inquiries from the public during the Fukushima Dai-ichi Nuclear Power Station accident. Proceedings of the International Symposium on Communicating Nuclear and Radiological Emergencies to the Public; 2018 Oct 1-5; Vienna, Austria.

14. Documents on a large-scale survey project by the Ministry of Education, Culture, Sports, Science and Technology regarding soil contamination caused by the accident at TEPCO's Fukushima Daiichi Nuclear Power Station [Internet]. Tokyo, Japan: Radioisotopes published by the Japan Radioisotope Association; 2013 [cited 2021 Mar 11]. Available from: https://www.jstage.jst. go.jp/browse/radioisotopes/62/10/_contents/-char/ja. 